\title{
Influence of age and disease severity on high resolution CT lung densitometry in asthma
} F Mitsunobu, T Mifune, K Ashida, Y Hosaki, H Tsugeno, M Okamoto, S Harada,
S Takata, Y Tanizaki

\begin{abstract}
Background-Low attenuation areas (LAA) on computed tomographic (CT) scans have been shown to represent emphysematous changes in patients with chronic obstructive pulmonary disease (COPD). However, the significance of LAA is still controversial in patients with asthma. This study was undertaken to assess the usefulness of lung CT densitometry in the detection of airspace enlargement in association with asthma severity.

Methods-Forty five asthmatic subjects and 15 non-smoking controls were studied to determine the influence of age, pulmonary function, and asthma severity on mean lung density (MLD) and the relative area of the lung showing attenuation values less than -950 HU $\left(\mathbf{R A}_{950}\right)$ on high resolution CT (HRCT) scans.

Results-In asthmatic patients both MLD and $\mathbf{R A}_{950}$ correlated with parameters of airflow limitation $\left(\% F_{E V}, \quad F E V_{1} / F V C\right.$, $\left.\% \mathrm{FEF}_{25-75}\right)$ and lung volume (\%TLC, $\%$ FRC, \%RV), but not with lung transfer factor (\%TLCO, \%TLCO/VA). The results of HRCT lung densitometry also correlated with patient age and severity of asthma. Conclusions-Decreased CT lung density in non-smoking asthmatics is related to airflow limitation, hyperinflation and aging, but not with lung transfer factor. (Thorax 2001;56:851-856)
\end{abstract}

Keywords: high resolution computed tomography; asthma severity; lung function; age

Medicine, Misas

Medical Branch,

Okayama University

Medical School, 827

Yamada, Misasa,

Tottori 682-0192, Japan

F Mitsunobu

T Mifune

K Ashida

Y Hosaki

$\mathrm{H}$ Tsugeno

M Okamoto

S Harada

S Takata

Y Tanizaki

Correspondence to: Dr F Mitsunobu

fumin@cc.okayama-u.ac.jp

Received 17 November 2000 Returned to authors

7 March 2001

Revised version received

6 July 2001

Accepted for publication

19 July 2001

Asthma is a disease characterised by airflow limitation that reverses spontaneously or in response to treatment. ${ }^{1}$ The nature of asthma as a chronic inflammatory disease of the airways is well recognised. ${ }^{2}$ This inflammation process leads to irreversible changes in the airway. ${ }^{3-5}$ Frequent airway and lung parenchymal changes associated with asthma are considered to be responsible for the irreversibility of airway obstruction, an outcome that is observed in many severe asthmatics. Emphysema, on the other hand, is defined pathologically as a process that results in the increase of distal airspaces with destruction of their walls without obvious fibrosis. ${ }^{6}$ The evidence for the presence of emphysema in asthmatic patients is controversial.

Numerous studies have demonstrated the usefulness of computed tomographic (CT) scanning and high resolution CT (HRCT) scanning to detect and quantify pulmonary emphysema in patients with chronic obstructive pulmonary disease (COPD), ${ }^{7-19}$ and a quantitative method using digital data as well as visual assessment of the scan are used to analyse the CT images. Low attenuation areas (LAA) on CT scans in vivo have been shown to represent macroscopic and/or microscopic emphysematous changes in the lungs of patients with COPD. ${ }^{7-12}$ However, one report has suggested that mean lung density (MLD) gives a good indication of hyperinflation rather than of emphysema. ${ }^{20}$

Some studies have investigated the use of CT lung densitometry in non-smoking asthmatic patients. ${ }^{21-24}$ One study suggested that the percentage of pixels below -900 Hounsfield Units (HU) at full expiration reflects air trapping in asthmatic patients and correlates with pulmonary function. ${ }^{21}$ Gevenois et al showed that acute expiratory airflow limitation and chronic hyperinflation did not influence the MLD or the relative area of the lungs showing attenuation values less than $-950 \mathrm{HU}\left(\mathrm{RA}_{950}\right)$ in nonsmoking asthmatic patients. ${ }^{22}$ They also found that CT lung densitometry was influenced by the total lung capacity (TLC) and age in healthy subjects. Biernacki et al observed that some patients with chronic stable asthma develop a reduction in CT lung density. ${ }^{23}$ In a previous study we reported that the MLD and $\mathrm{RA}_{950}$ correlated significantly with the forced expiratory volume in 1 second $\left(\mathrm{FEV}_{1}\right)$, but not with the transfer factor for carbon monoxide (TLCO) in 10 non-smoking asthmatic subjects. ${ }^{24}$ However, to our knowledge, the relationship between the findings of CT lung densitometry and asthma severity has not been studied.
The purpose of this study was to evaluate the use of HRCT lung densitometry in detecting distal airspace enlargement in asthma. We investigated the influence of age, pulmonary function tests, and asthma severity on the results of HRCT lung densitometry. We examined MLD and $\mathrm{RA}_{950}$ by HRCT scanning and correlated the findings with lung function in 45 asthmatics and 15 healthy non-smoking controls.

\section{Methods}

SUBJECTS

Forty five asthmatic subjects (27 women) of mean (SD) age 60.0 (12.1) years (range 24-80) and 15 normal subjects (10 women) of mean (SD) age 64.2 (10.4) years (range 44-79) were recruited from Misasa Medical Branch. Asthma was diagnosed according to 
the definition proposed by the American Thoracic Society. ${ }^{25}$ All subjects with asthma had episodic symptoms of wheezing and coughing and experienced symptomatic relief and reversible airway response with an accompanying increase in $\mathrm{FEV}_{1}$ exceeding $20 \%$ following treatment with $\beta_{2}$ adrenergic agonists. None of the asthmatics had a history of clinically demonstrable tuberculosis or allergic bronchopulmonary aspergillosis as defined by the criteria of Rosenberg et $a l^{26}$ The asthmatic subjects were stable with no changes in asthma symptoms and medication for at least 1 month, except for the use of short acting inhaled $\beta_{2}$ agonists. Normal subjects had no chest symptoms with $\mathrm{FEV}_{1}>90 \%$ predicted. All subjects were lifelong non-smokers. No subjects had a history of upper respiratory tract infection within the month prior to entry to the study. Subjects underwent a chest HRCT scan and pulmonary function tests on the same day.

Patients were classified into three groups based on severity of asthma according to the guidelines of the National Institutes of Health/ World Health Organization (NIH/WHO). ${ }^{27}$ Mild asthma was defined as symptoms occurring less than once a day, night-time symptoms less than once a week, and $\mathrm{FEV}_{1} \geqslant 80 \%$ predicted; moderate asthma was defined as patients having daily symptoms, requiring daily use of inhaled short acting $\beta_{2}$ agonists, and pretreatment $\mathrm{FEV}_{1}$ of $60-80 \%$ predicted; severe asthma was defined as patients having continuous symptoms, frequent exacerbations, limited physical activity, frequent night-time symptoms, and pretreatment $\mathrm{FEV}_{1} \leqslant 60 \%$ predicted.

All the asthmatic patients were considered to be stable within the above classification; stability was defined as follows: subjects with mild asthma maintained on a short acting inhaled $\beta_{2}$ agonist on an "as needed" basis; those with moderate asthma maintained with scheduled medium dose inhaled corticosteroids (beclomethasone dipropionate (BDP) 400-1000 $\mu \mathrm{g}$ daily) and short acting $\beta_{2}$ agonist on an as needed basis for daily breakthrough symptoms; and subjects with severe asthma on oral prednisolone and high dose inhaled corticosteroids (BDP 1000-2000 $\mu \mathrm{g}$ daily).

The onset and duration of asthma were established by careful review of patient history and complete physical examination. Atopy was evaluated by a combination of history of allergies, skin tests, and the presence of serum $\operatorname{IgE}$ antibodies specific to 12 common aeroallergens including house dust mite, pollens, moulds, and animal danders. Serum specific IgE was measured using the Pharmacia CAP system (Pharmacia Diagnostics AB, Uppsala, Sweden). Atopic patients were defined as those who had a positive skin test and/or the presence of allergen specific IgE.

Informed consent was obtained from all subjects and the study protocol was approved by the ethics committee of our institution.

PULMONARY FUNCTION TESTS

Spirometric tests were performed using a Chestac 33 (Chest Co, Tokyo, Japan). The following measurements were performed on all
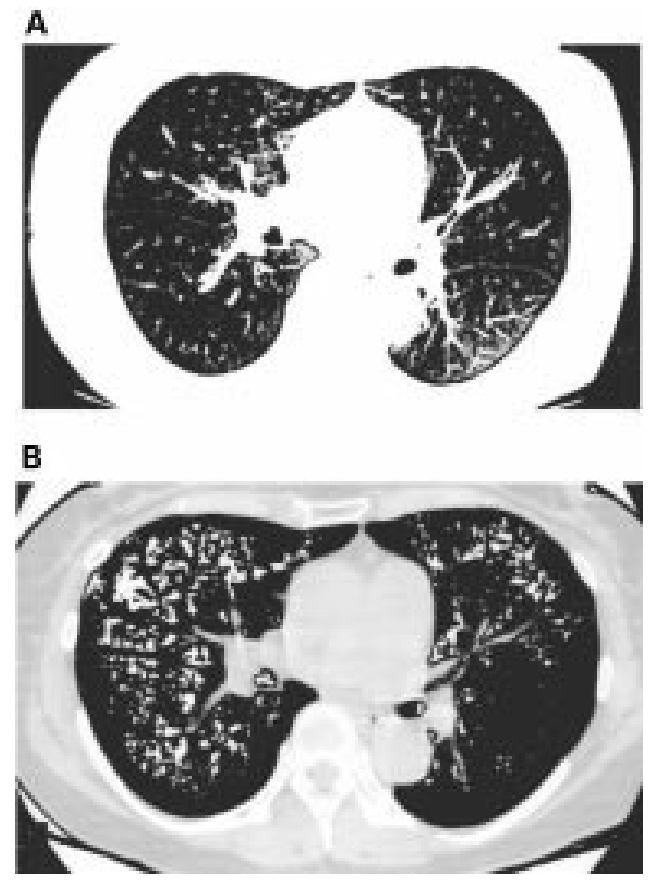

Figure 1 (A) Representative HRCT image of a middle lung section in an asthmatic patient. The mean lung density (MLD) is $-906.0 \mathrm{HU}$ and the relative area of the lung showing attenuation values less than $-950 \mathrm{HU}\left(R A_{95}\right)$ is $15.6 \%$. (B) The same image as in (A) but with the addition of white highlighting of areas with attenuation values less than $-950 \mathrm{HU}$.

subjects: forced vital capacity (FVC), $\mathrm{FEV}_{1}$, $\mathrm{FEV}_{1} / \mathrm{FVC}$, and mean forced expiratory flow $\left(\mathrm{FEF}_{25-75}\right)$. Total lung capacity (TLC), functional residual capacity (FRC), residual volume (RV), and RV/TLC were measured using body plethysmography (Autobox 2800, Chest Co, Tokyo, Japan). The carbon monoxide transfer factor (TLCO) and TLCO/alveolar volume (VA) were measured according to the single breath technique using Chestac 33. FVC, $\mathrm{FEV}_{1}, \mathrm{FEF}_{25-75}$, TLC, FRC, RV, TLCO, and TLCO/VA measurements for each patient were expressed as a percentage of their predicted values according to the prediction equations of the Japanese Society of Chest Diseases. $^{28}$

\section{COMPUTED TOMOGRAPHY}

Each patient underwent a non-contrast HRCT scan using a Toshiba Xpeed scanner (Toshiba, Tokyo, Japan) with $2 \mathrm{~mm}$ collimation, scanning time of 2.7 seconds, voltage of $120 \mathrm{kVp}$, and current of $200 \mathrm{~mA}$. All HRCT scans were performed in supine patients following maximal inspiration. The images were reconstructed on a $30 \mathrm{~cm}$ field of view (FOV) using a standard algorithm (FC 1). Three HRCT scans were performed for determination of MLD and LAA; an upper section was obtained at the top of the aortic arch, a middle section was taken at the origin of the lower lobe bronchus, and a lower section was taken $3 \mathrm{~cm}$ above the top of the diaphragm, as described by Miniati et al. ${ }^{29}$

A preliminary study revealed that the density of the lung area was less than $-750 \mathrm{HU}$ whereas the density of the chest wall and mediastinum was greater than $-750 \mathrm{HU}$. Using these results, the areas with a density less than 
Table 1 Clinical characteristics and pulmonary function tests of study subjects

\begin{tabular}{|c|c|c|c|c|}
\hline & Controls $(n=15)$ & Mild asthma $(n=15)$ & Moderate asthma $(n=15)$ & Severe asthma $(n=15)$ \\
\hline $\operatorname{Sex}(F / M)$ & $10 / 5$ & $10 / 5$ & $9 / 6$ & $8 / 7$ \\
\hline Age (years) ${ }^{\star}$ & $64.2(10.4)$ & $57.2(13.0)$ & $58.2(13.3)$ & $66.3(7.8)$ \\
\hline Duration of asthma (years) $\dagger$ & NA & $8.0(3-22)$ & $10.0(4-25)$ & $15.5(5-36)$ \\
\hline Atopic/non-atopic & $0 / 15$ & $8 / 7$ & $8 / 7$ & $8 / 7$ \\
\hline FVC $(\% \text { pred })^{\star}$ & $111.5(8.3)$ & $106.2(13.7)$ & $102.5(19.3)$ & $94.6(12.6)$ \\
\hline $\mathrm{FEV}_{1}(\% \text { pred })^{\star} \ddagger$ & $107.8(11.4)$ & $98.6(10.2)$ & $71.3(3.9)$ & $52.6(6.2)$ \\
\hline $\mathrm{FEV}_{1} / \mathrm{FVC}(\%) \star \mathrm{S}$ & $79.5(4.2)$ & $76.6(9.4)$ & $61.5(7.5)$ & $52.4(8.5)$ \\
\hline $\operatorname{TLC}(\% \text { pred })^{\star}$ & $103.8(6.1)$ & $108.3(9.9)$ & $112.2(15.0)$ & $117.5(13.9)$ \\
\hline FRC (\% pred $)^{\star}$ & $97.0(11.3)$ & $96.6(14.9)$ & $101.5(20.1)$ & $107.9(18.2)$ \\
\hline $\mathrm{RV}(\%$ pred $) \star \AA$ & $100.7(11.6)$ & $108.0(16.1)$ & $121.7(34.7)$ & $143.8(23.9)$ \\
\hline TLCO $(\% \text { pred })^{\star}$ & $102.4(8.2)$ & $101.8(12.7)$ & $102.6(12.6)$ & $105.1(13.4)$ \\
\hline TLCO/VA $(\% \text { pred })^{\star}$ & $105.5(6.0)$ & $108.6(15.8)$ & $111.6(16.2)$ & $113.1(13.7)$ \\
\hline \multicolumn{5}{|l|}{ Medication } \\
\hline Inhaled BDP (mg/day)* & NA & 0 & 706 (103) & $1120(101)$ \\
\hline Systemic corticosteroids (n) & NA & 0 & 0 & 15 \\
\hline
\end{tabular}

FVC $=$ forced vital capacity $\%$ pred $=$ percentage of the predicted value $\mathrm{FEV}_{1}=$ forced expiratory volume in 1 second $;$ TLC $=$ total lung capacity; FRC = forced residual capacity; RV = residual volume; TLCO = lung transfer factor for carbon monoxide; VA = alveolar volume; $\mathrm{BDP}=$ beclomethasone dipropionate; $\mathrm{NA}=$ not available.

$\star$ Values are expressed as mean (SD).

+Values are expressed as median (range).

$\ddagger$ Controls and patients with mild asthma were significantly higher than those with either moderate $(p<0.001)$ or severe $(p<0.001)$ asthma, and those with moderate asthma were significantly higher than severe asthma $(\mathrm{p}<0.001)$.

$§$ Controls and patients with mild asthma were significantly higher than those with either moderate $(p<0.05)$ or severe $(p<0.001)$ asthma, and those with moderate asthma were significantly higher than severe asthma $(\mathrm{p}<0.05)$.

qPatients with severe asthma were significantly higher than either controls or those with mild asthma $(\mathrm{p}<0.01)$.

$-750 \mathrm{HU}$ inside the body were considered to be lung areas. The cut off level between the normal lung density area and LAA was defined as $-950 \mathrm{HU}$ because we found that $1 \mathrm{SD}$ below the mean density of the lungs from 15 non-smoking control subjects was $-949 \mathrm{HU}$. An HRCT image and LAA (less than $-950 \mathrm{HU}$ ) of a representative asthmatic patient are shown in fig 1 . The MLD and $\mathrm{RA}_{950}$ were calculated at all three anatomical levels and averaged.

\section{STATISTICAL ANALYSIS}

The results are expressed as mean (SD). Pearson's correlation coefficients were calculated to determine the relationship between each variable. Stepwise multiple regression analysis was used to evaluate the relationship between the HRCT parameters, lung function, and age. The Mann-Whitney $U$ test and analysis of variance (ANOVA) with Bonferroni/Dunn correction were used to compare groups. A p value of $<0.05$ was regarded as statistically significant.

Table 2 Correlation ( $r$ values) between lung function and HRCT parameters in asthmatic patients $(n=45)$

\begin{tabular}{|c|c|c|c|c|}
\hline & \multicolumn{2}{|c|}{$M L D(H U)$} & \multicolumn{2}{|c|}{$R A_{950}(\%)$} \\
\hline & rvalue & p value & rvalue & $p$ value \\
\hline Age (years) & -0.456 & 0.0018 & 0.405 & 0.0062 \\
\hline FVC (\% pred) & 0.116 & NS & -0.278 & NS \\
\hline $\mathrm{FEV}_{1}(\%$ pred $)$ & 0.666 & $<0.0001$ & -0.746 & $<0.0001$ \\
\hline $\mathrm{FEV}_{1} / \mathrm{FVC}(\%)$ & 0.556 & $<0.0001$ & -0.574 & $<0.0001$ \\
\hline $\mathrm{FEF}_{25-75}(\%$ pred $)$ & 0.441 & 0.0032 & -0.495 & 0.0006 \\
\hline TLC $(\%$ pred $)$ & -0.379 & 0.0126 & 0.332 & 0.0358 \\
\hline FRC (\% pred) & -0.312 & 0.0448 & 0.345 & 0.0246 \\
\hline RV (\% pred) & -0.381 & 0.0120 & 0.511 & 0.0004 \\
\hline RV/TLC (\%) & -0.239 & NS & 0.341 & 0.0251 \\
\hline TLCO (\% pred) & -0.115 & NS & 0.096 & NS \\
\hline TLCO/VA ( $\%$ pred $)$ & -0.056 & NS & -0.008 & NS \\
\hline
\end{tabular}

HRCT $=$ high resolution computed tomography; $\mathrm{MLD}=$ mean lung density; $\mathrm{HU}=$ Hounsfield units; $\mathrm{RA}_{950}=$ relative area of the lung with attenuation values lower than $-950 \mathrm{HU}$; $\mathrm{FEF}_{25-75}=$ mean forced expiratory flow during the middle half of the FVC; NS = not significant. Other abbreviations as in footnote to table 1 .

\section{Results}

PATIENT CHARACTERISTICS

Patient characteristics, lung function tests, and current medications are shown in table 1. There were no statistically significant differences in age or sex distribution between patients with mild, moderate, or severe asthma and control subjects. The duration of asthma and the prevalence of atopy did not differ between the three asthmatic subgroups. There were significant differences in $\% \mathrm{FEV}_{1}$ and $\% \mathrm{FEV}_{1} / \mathrm{FVC}$ among the three asthmatic subgroups. The $\% \mathrm{RV}$ values were significantly higher in those with severe asthma than in control subjects or those with mild asthma. There were no statistically significant differences in $\%$ FVC, \% $\%$ TLCO/VA between the groups. All asthmatic patients were treated with inhaled $\beta_{2}$ agonists. The mean dose of inhaled BDP was $706 \mu \mathrm{g} /$ day for patients with moderate asthma and 1120 $\mu \mathrm{g} /$ day for those with severe asthma. The mean dose of oral prednisolone, used only in patients with severe asthma, was $6.8 \mathrm{mg} /$ day. Oral theophylline was administrated to patients with moderate and severe asthma.

RELATIONSHIP BETWEEN HRCT LUNG DENSITOMETRY AND PHYSIOLOGICAL FACTORS The relationships between MLD and $\mathrm{RA}_{950}$ and age and pulmonary function tests in the 45 asthmatic patients examined are shown in table 2. MLD correlated significantly with patient age, $\% \mathrm{FEV}_{1}, \mathrm{FEV}_{1} / \mathrm{FVC}, \% \mathrm{FEF}_{25-75}, \% \mathrm{TLC}$, $\% \mathrm{FRC}$, and $\% \mathrm{RV}$ but not with $\% \mathrm{FVC}$, RV/TLC, \% TLCO, or \% TLCO/VA. We also found that $\mathrm{RA}_{950}$ correlated significantly with patient age, $\% \mathrm{FEV}_{1}, \mathrm{FEV}_{1} / \mathrm{FVC}, \% \mathrm{FEF}_{25-75}$, $\%$ TLC, \%FRC, \%RV, and RV/TLC but not with $\%$ FVC, $\%$ TLCO, or $\%$ TLCO/VA. However, there was no statistically significant correlation between HRCT findings and $\% \mathrm{FEV}_{1}, \mathrm{FEV}_{1} /$ FVC, or $\% \mathrm{FEF}_{25-75}$ in the 15 healthy controls (data not shown). These data suggest that 
Table 3 Multiple regression analysis of HRCT parameters using age and pulmonary function tests in asthmatic subjects $(n=45)$

\begin{tabular}{|c|c|c|c|c|c|c|}
\hline \multirow[b]{2}{*}{ Predictor variable } & \multicolumn{3}{|c|}{$M L D(H U)\left(R^{2}=0.0524\right)$} & \multicolumn{3}{|c|}{$R A_{950}(\%)\left(R^{2}=0.611\right)$} \\
\hline & $\begin{array}{l}\text { Regression } \\
\text { coefficient }\end{array}$ & $95 \% C I$ & $p$ value & $\begin{array}{l}\text { Regression } \\
\text { coefficient }\end{array}$ & $95 \% C I$ & $p$ value \\
\hline Age (years) & -0.410 & -0.773 to -0.047 & 0.0279 & 0.159 & 0.007 to 0.310 & 0.0411 \\
\hline FVC (\% pred) & - & - & - & - & - & - \\
\hline $\mathrm{FEV}_{1}(\%$ pred $)$ & 0.503 & 0.289 to 0.717 & $<0.0001$ & -0.272 & -0.361 to -0.183 & $<0.0001$ \\
\hline $\mathrm{FEV}_{1} / \mathrm{FVC}(\%)$ & - & - & - & - & - & - \\
\hline $\mathrm{FEF}_{25-75}(\%$ pred $)$ & - & - & - & - & - & - \\
\hline TLC (\% pred) & -0.366 & -0.673 to -0.059 & 0.0207 & - & - & - \\
\hline FRC (\% pred) & - & - & - & 0.126 & 0.030 to 0.221 & 0.0112 \\
\hline RV (\% pred) & - & - & - & - & - & - \\
\hline RV/TLC (\%) & - & - & - & - & - & - \\
\hline TLCo (\% pred) & - & - & - & - & - & - \\
\hline TLCO/VA (\% pred) & - & - & - & - & - & - \\
\hline
\end{tabular}

$R^{2}=$ coefficient of determination.

Missing values indicate that independent variables were not statistically significant.

Abbreviations as in footnote to tables 1 and 2 .

HRCT lung densitometry in asthmatic subjects has significant correlations with patient age and pulmonary function parameters regarding flow limitation and lung volume, but dose not correlate with lung transfer factor.

MULTIPLE REGRESSION ANALYSIS

The results of stepwise multiple regression analysis using MLD and $\mathrm{RA}_{950}$ as dependent variables are shown in table 3. The MLD was predicted by the combination of patient age $(p=0.0279), \% \mathrm{FEV}_{1}(\mathrm{p}<0.0001)$, and \% TLC $(\mathrm{p}=0.0207)$. The $\mathrm{RA}_{950}$ was also predicted by the combination of patient age $(p=0.0411)$, $\% \mathrm{FEV}_{1}(\mathrm{p}<0.0001)$, and \%FRC $(\mathrm{p}=0.0112)$.

\section{RELATIONSHIP BETWEEN HRCT LUNG}

DENSITOMETRY AND ASTHMA SEVERITY

The MLD values for control subjects and patients with mild, moderate, and severe asthma were -867.3 (20.7) HU, -874.8 (17.2) HU, -893.8 (8.1) HU, and -910.5 (11.5) HU. The $\mathrm{RA}_{950}$ was 3.1 (3.2)\% in control subjects, $5.1(2.3) \%$ in patients with mild asthma, 10.2 (3.7)\% in those with moderate asthma, and $22.9(6.6) \%$ in those with severe asthma. Both MLD and $\mathrm{RA}_{950}$ were significantly different between the groups $(p<0.001$ by ANOVA). There was a significant correlation between asthma severity and MLD or $\mathrm{RA}_{950}(\mathrm{p}<0.001)$. However, no significant

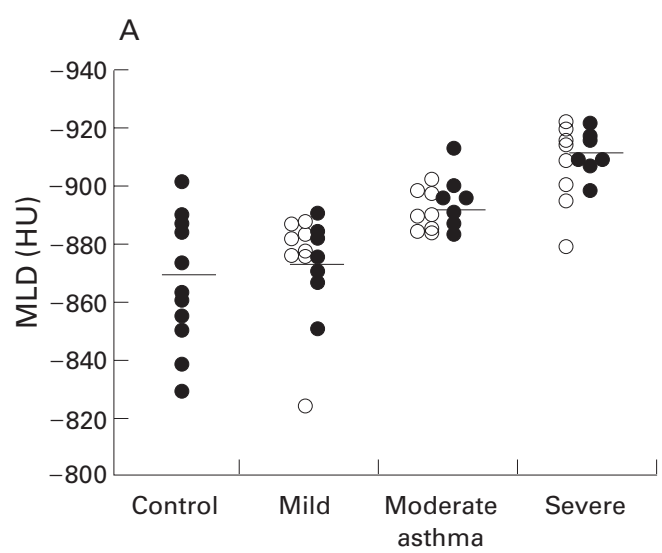

difference in MLD or $\mathrm{RA}_{950}$ was found between atopic and non-atopic asthmatic subjects with the same asthma severity (fig $2 \mathrm{~A}, \mathrm{~B}$ ).

\section{Discussion}

We have examined the relationship between the results of HRCT lung densitometry (MLD and $\mathrm{RA}_{950}$ ) at maximal inspiration and pulmonary function, patient age, and asthma severity. Our study showed that at least some patients with asthma have decreased attenuation of HRCT lung density which was influenced by age, lung volumes, airflow limitation, and asthma severity, but not by lung transfer factor.

Increases in the LAA of patients with COPD have been reported to reflect the pathological changes of pulmonary emphysema. ${ }^{7-12}$ The CT measurement of LAA correlates well with transfer factor, a sensitive index of pulmonary emphysema, and measurements of airway obstruction. ${ }^{10-19} 29$ On the other hand, MLD may be linearly related to the fraction of air in the lungs and therefore may not represent the pathological changes of emphysema, given its non-homogenous distribution. Heremans et al found that, in patients with COPD, MLD correlates with pulmonary function indices of airway obstruction and hyperinflation but not with indices that are considered more specific for emphysema (TLCO and static lung compliance) ${ }^{20}$ It is likely that the relationship between

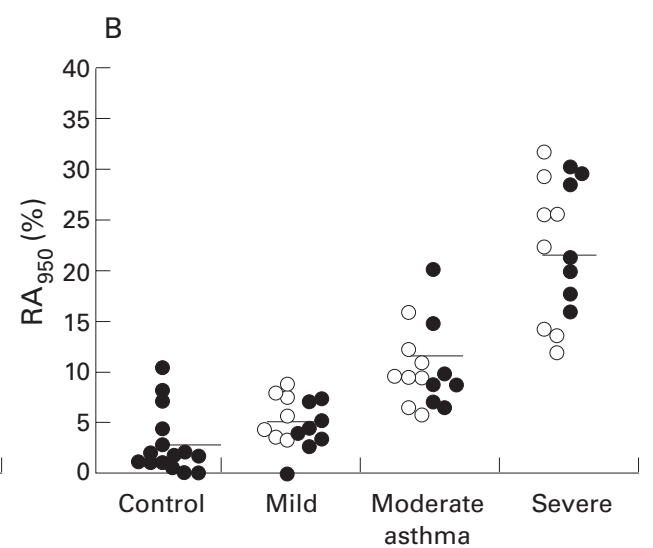

Figure 2 Relationship between (A) mean lung density (MLD) and (B) relative area of the lung showing attenuation values less than $-950 \mathrm{HU}\left(R A_{950}\right)$ and the severity and type of asthma. The difference between the four groups was significant by analysis of variance $($ ANOVA, $p<0.001)$. Open circles = atopic subjects, closed circles = non-atopic subjects. Solid horizontal line $=$ mean. 
MLD and lung function differs from that between $\mathrm{RA}_{950}$ and lung function.

In efforts to minimise radiation exposure we calculated both MLD and $\mathrm{RA}_{950}$ using three cross sections of the lung (upper, middle, and lower). This was considered adequate as Mishima et al described an accurate correlation between the percentage of LAA detected from 10 sections (from apex to base of the lung) versus three sections in patients with COPD. ${ }^{19}$

We used $-950 \mathrm{HU}$ as the cut off level between the normal lung density area and LAA. Previous studies have used variable levels ranging from -900 to $-960 \mathrm{HU}^{8-11} 131417-192930$ This discrepancy may be attributed to variations between the CT scanning techniques (equipment and reconstruction of images) as well as CT images (conventional $v$ high resolution). Using HRCT scans of 15 healthy controls, we found the mean MLD -1SD to be -949 HU.

We obtained images after deep inspiration. Gevenois et al reported that inspiratory CT images were more accurate than expiratory images for quantifying pulmonary emphysema. ${ }^{11}$ They speculated that abnormalities in the expiratory CT scan are more reflective of air trapping than of a reduction in terminal airspace volume. Eda et $a l^{11}$ found that helical CT images acquired at maximal expiration reflected air trapping whereas CT visual scores at full inspiration showed significant correlation with emphysema. We therefore consider inspiratory CT scans to be more suitable than expiratory CT scans for determining whether emphysema is present in asthma.

We found that both $\mathrm{RA}_{950}$ and MLD strongly correlated with measurements of airflow limitation $\left(\% \mathrm{FEV}_{1}, \mathrm{FEV}_{1} / \mathrm{FVC}\right)$ and also significantly correlated with indices indicating hyperinflation (\% TLC) and air trapping (\%RV). $\mathrm{RA}_{950}$ and MLD did not correlate with TLCO or TLCO/VA, two values which have been shown previously to correlate with emphysema. ${ }^{14} 16$ 32-34 We also found no statistically significant difference in CT lung densitometry between patients with mild asthma and non-atopic controls. However, $\mathrm{RA}_{950}$ increased and $\mathrm{MLD}$ decreased significantly with the severity of asthma.

Biernacki et al observed that patients with chronic stable asthma and COPD had a reduction in CT lung density, similar to our results. ${ }^{23}$ However, they also found that the lowest fifth percentile CT numbers were similar before and after treatment with nebulised $\beta_{2}$ agonist, and at the end of an exacerbation and 6 weeks later in five patients with asthma. They concluded that less restricted airflow and diminished chronic overinflation did not affect the lowest fifth percentile CT number. Gevenois et al failed to find any significant changes in $\mathrm{RA}_{950}$ during allergic challenge tests despite a decrease in $\mathrm{FEV}_{1}$ and an increase in RV and FRC. ${ }^{22}$ The MLD and RA $_{950}$ of 10 asthmatics with an increased TLC did not significantly differ from those of healthy subjects. They concluded that hyperinflation and airflow obstruction without emphysematous lung destruction does not influence densitometric measurements obtained from inspiratory scans. The difference between the findings of their study and ours may be due to the fact that our subjects are older than theirs.

By multiple regression analysis we have shown that $\mathrm{RA}_{950}$ correlates with age, \%FRC, and $\% \mathrm{FEV}_{1}$, and that MLD correlates with age, \% TLC, and $\% \mathrm{FEV}_{1}$. Both MLD and $\mathrm{RA}_{950}$ were found to be influenced by age, lung volume, and chronic airflow limitation. Gevenois et al reported that both MLD and $\mathrm{RA}_{950}$ are influenced by TLC and, to a lesser extent, by age in healthy subjects. ${ }^{22}$ This was further supported by a longitudinal study by Soejima et al who showed that aging increased airspace abnormalities on HRCT images of nonsmoking subjects over a study period of 5 years. $^{35}$

We found a strong correlation between lung CT density and airflow limitation, a weak correlation with age and lung volumes, and no correlation with transfer factor. The likely reason is that airflow measurements have a wide range whereas age and lung volume measurements have a narrow range. We also speculate that the decreased lung density in non-smoking asthmatic subjects is related to simple gas trapping rather than a significant change in the recoil properties. Further study is needed to examine whether there are significant changes in the recoil properties of asthmatic lungs.

Paganin et al reported a significant increase in the extent of permanent HRCT scan abnormalities with increasing severity and duration of symptoms, both in patients with allergic and non-allergic asthma. ${ }^{36}$ They further reported that airway remodelling is more common in patients with non-allergic than allergic asthma, even when the duration of disease was similar. They speculated that the anatomical changes in patients with non-allergic asthma were related to advanced age and mechanism of asthma. We observed that $\mathrm{RA}_{950}$ and MLD values were associated with severity of asthma but not with the type of asthma. Our findings may be explained by the fact that our subjects are too advanced in age to show differences between the two groups. Further study is needed to clarify the relationship between asthma type and the results of CT lung densitometry in younger subjects.

We conclude that decreased HRCT lung density in non-smoking asthmatic patients is related to airflow limitation, hyperinflation and aging, but not to lung transfer factor. The decreased HRCT lung density may represent microscopic emphysema or chronic overinflation. We suggest that HRCT scanning may provide useful information about the severity of chronic asthma.

The authors thank Mr M Nakai for his technical assistance with CT scanning.

No funding in the form of grants, gifts, equipment, or pharmaceutical products was received for this study.

1 Fletcher CM, Pride NB. Definition of emphysema, chronic bronchitis, asthma and airway obstruction. 25 years from CIBA symposium. Thorax 1984;39:81-5.

2 Djukanovic R, Roche WR, Wilson JW, et al. Mucosal inflammation in asthma. Am Rev Respir Dis 1990;142:43457 
3 Ebina M, Takahashi T, Chiba T, et al. Cellular hypertrophy and hyperplasia of airway smooth muscles underlying bronchial asthma. A 3-D morphometric study. Am Rev : $720-6$.

4 Carroll N, Elliot J, Morton A, et al. The structure of large and small airways in nonfatal and fatal asthma. Am Rev Respir Dis 1993;147:405-10.

5 Bousquet J, Chanez P, Lacoste JY, et al. Asthma: a disease remodelling the airways. Allergy 1992;47:3-11.

6 Snider GL, Kleinermann J, Thurlbeck WM, et al. The definition of emphysema. Report of a National Heart, Lung and Blood Institute, Division of Lung Disease Workshop. Am Rev Rrespir Dis 1985;132:182-5.

7 Bergin C, Müller N, Nichols DM, et al. The diagnosis of emphysema. A computed tomographic-pathologic correlation. Am Rev Respir Dis 1986;133:541-6.

8 Müller NL, Staples CA, Miller RR, et al. "Density mask". An objective method to quantitate emphysema using comAn objective method to quantitate emphyser

9 Guted tomography. Chest 1988;94:782-7. of computed density and macroscopic morphometry in pulmonary emphysema. Am $\mathcal{f}$ Respir Crit Care Med pil

10 Gevenois PA, Vuyst PD, Maertelaer VD, et al. Comparison of computed density and microscopic morphometry in pulmonary emphysema. Am $\mathcal{F}$ Respir Crit Care Med 1996;154:187-92.

11 Gevenois PA, Vuyst PD, Sy $M$, et al. Pulmonary emphysema: quatitative CT during expiration. Radiology 1996;199:825-9.

12 Kuwano K, Matsuba K, Ikeda T, et al. The diagnosis of mild emphysema. Comparison of computed tomography and pathology scores. Am Rev Respir Dis 1990;141:169-78.

13 Sakai N, Mishima M, Nishimura K, et al. An automated method to assess the distribution of low attenuation areas on chest CT scans in chronic pulmonary emphysema patients. Chest 1994;106:1319-25.

14 Kinsella M, Müller NL, Abboud RT, et al. Quantitation of emphysema by computed tomography using a "density mask" program and correlation

15 Coxson HO, Rogers RM, Whittall KP, et al. A quantification of the lung surface area in emphysema using computed tomography. Am f Respir Crit Care Med 1999;159:851-6.

16 Gould GA, MacNee W, Mclean A, et al. CT measurement of lung density in life can quantitate distal air-space enlargement: an essential defining feature of human emphysema. Am Rev Respir Dis 1988;137:380-92.

17 Nakano Y, Sakai H, Muro S, et al. Comparison of low attenuation areas on CT between inner and outer segments of the lung in COPD patients: Incidence and contribution to lung function. Thorax 1999;54:384-9.

18 Mishima M, Hirai $\mathrm{T}$, Itoh $\mathrm{H}$, et al. Complexity of terminal airspace geometry assessed by lung computed tomography in normal subjects and patients with chronic obstructive pulmonary disease. Proc Natl Acad Sci USA 1999;96:882934 .

19 Mishima $\mathrm{M}$, Itoh $\mathrm{H}$, Sakai $\mathrm{H}$, et al. Optimized scanning conditions of high resolution CT in the follow-up of pulmon $380-4$.
20 Heremans A, Verschakelen JA, Van fraeyenhoven L, et al. Measurement of lung density by means of quantitative CT scanning. A study of correlations with pulmonary function chts. Chest 1992:102:805-11.

21 Newman KB, Lynch DA, Newman LS, et al. Quantitative computed tomography detects air trapping due to asthma. Chest 1994;106:105-9.

22 Gevenois PA, Scillia P, de Maertelaer V, et al. The effects of age, sex, lung size, and hyperinflation on CT lung densitometory. AfR 1996;167:1169-73.

23 Biernacki W, Redpath AT, Best JJ, et al. Measurement of CT lung density in patients with chronic asthma. Eur Respir $\mathcal{F}$ 1997; 10:2455-9.

24 Mitsunobu F, Mifune T, Ashida K, et al. Low attenuation areas of the lungs on high-resolution computed tomography in asthma. F Asthma 2001;38:413-22.

25 American Thoracic Society. Standards for the diagnosis and care of patients with chronic obstructive pulmonary disease (COPD) and asthma. Am Rev Respir Dis 1987;136:225-44.

26 Rosenberg M, Patterson R, Mintzer R, et al. Clinical and immunologic criteria for the diagnosis of allergic bronchopulmonary aspergillosis. Ann Intern Med 1977;86:40514.

27 National Institutes of Health: National Heart, Lung, and Blood Institute. Guidelines for the diagnosis and management of asthma. Publication No. 97-4051. Washington: National Institutes of Health, 1997 .

28 Japanese Society of Chest Diseases. Standards of pulmonary function tests for Japanese. Fapanese F Thorac Dis 1993;31: appendix

29 Miniati M, Filippi E, Falaschi F, et al. Radiologic evaluation of emphysema in patients with chronic obstructive pulmonary disease: chest radiology versus high resolution computed tomography. Am $\mathcal{F}$ Respir Crit Care Med 1995; 151:1359-67.

30 Bae KT, Slone RM, Gierada DS, et al. Patients with emphysema: quantitative CT analysis before and after lung volume reduction surgery. Work in progress. Radiology 1997;203:705-14

31 Eda S, Kubo K, Fujimoto K, et al. The relations between expiratory chest CT using helical CT and pulmonary func-
tion tests in emphysema. Am f Respir Crit Care Med 1997; 155:1290-4.

32 Petty TL, Silvers GW, Stanford RE. Functional correlations with mild and moderate emphysema in excised lungs. $\mathrm{Am}$ Rev Respir Dis 1981;124:700-4.

33 Gould GA, Redpath AT, Ryan M, et al. Parenchymal emphysema measured by CT lung density correlates with ung function in patients with bullous disease. Eur Respir $\mathcal{F}$ 1993;6:698-704.

34 Gould GA, Redpath AT, Ryan M, et al. Lung CT density correlates with measurements of airflow limitation and the diffusing capacity. Eur Respir f 1991;4:141-6.

35 Soejima K, Yamaguchi K, Kohda E, et al. Longitudinal follow-up study of smoking-induced lung density changes by high-resolution computed tomography. Am $\mathcal{F}$ Respir Crit Care Med 2000;161:1264-73.

36 Paganin F, Seneterre E, Chanez P, et al. Computed tomography of the lungs in asthma: influence of disease severity and etiology. Am $\mathcal{F}$ Respir Crit Care Med 1996;153:110-4. 


\section{LETTERS TO THE EDITOR}

\section{BMD and airways disease}

The papers recently published in Thorax by Tattersfield et $a l^{1}$ and Walsh et $a l^{2}$ offer important information about the possible adverse affects of corticosteroids on bone mineral density (BMD). Tattersfield and her colleagues reported no change in BMD with inhaled corticosteroids for mild asthma, while Walsh et al found a dose related increase in the incidence of fractures in those taking oral corticosteroids. We would like to report our study of BMD in patients with airways disease, which reinforces these findings and highlights men as being particularly at risk.

We prospectively studied 100 consecutive outpatients (44 men) with steroid responsive airways disease. The formulation and cumulative dose of corticosteroid was recorded in each individual, together with all prescribed prophylaxis for osteoporosis. Bone mineral density was measured in the non-dominant forearm. We found no relationship between inhaled corticosteroid dose and BMD. Mean BMD was significantly reduced in those on oral as opposed to inhaled steroids. In men the mean Z scores for those on inhaled and oral corticosteroids were 0.1 and -0.6 , respectively $(\mathrm{p}=0.07)$, while women had mean $\mathrm{Z}$ scores of 0.5 and -0.3 for inhaled and oral corticosteroids, respectively $(\mathrm{p}=0.016)$. Our patient numbers were insufficient to confirm a dose response. The surprising result was that men were more likely to meet the WHO criteria for osteoporosis than women ( $25 \% v 12.5 \%)$. This result is explained at least in part by the use of prophylaxis which was prescribed to 21 women but to only two men. Of those on regular oral steroids, only $5.5 \%$ of men received prophylaxis compared with $62.5 \%$ of women. Similar results have been reported in other chronic diseases, with a greater reduction in BMD being reported in men with cystic fibrosis.

Unfortunately it appears to have been assumed that men are protected from osteoporosis by virtue of their gender. When chronic disease is treated with oral corticosteroids, both men and women are equally at risk of osteoporosis and all should be considered for prophylaxis

C Elmer, P Bartholemew, A Lapworth, P Turner, C Kelly

Department of Medicine, Queen Elizabeth Hospital, Gateshead NE9 6SX, UK

\section{References}

1 Tattersfield AE, Town GI, Johnell O, et al. Bone mineral density in subjects with mild asthma randomised to treatment with inhaled corticosteroids or non-corticosteroid treatment for two years. Thorax $2001 ; 56: 272-8$.

2 Walsh LJ, Wong CA, Oborne J, et al. Adverse effect of oral corticosteroids in relation to dose in patients with lung disease. Thorax 2001:56:279-84.

3 Conway SP, Morton AM, Oldroyd B, et al. Osteoporosis and osteopenia in adults and adolescents in cystic fibrosis: prevalence and associated factors. Thorax 2000;55:798804

\section{AHR in asthma}

Peat et al have contributed a helpful review to the debate on techniques for measuring
If you have a burning desire to respond to a paper published in Thorax, why not make use of our "rapid response" option? Log on to our website (www.thoraxjnl.com), find the paper that interests you, and send your response via email by clicking on the "eletters" option in the box at the top right hand corner.

Providing it isn't libellous or obscene, it will be posted within seven days. You can retrieve it by clicking on "read eletters" on our homepage.

The editors will decide as before whether to also publish it in a future paper issue.

asthma in population studies. However, they have endorsed airway hyperresponsiveness (AHR) while neatly sidestepping the issue of what test they are discussing. Inhaled provocation tests used in epidemiological work have included histamine, methacholine, hypertonic saline, cold air, and adenosine. Exercise provocation tests have also been used. Peat et al have previously shown that exercise and histamine challenges may define different groups of children, ${ }^{2}$ and we have shown that longer term repeatability of a free running exercise provocation test is poo within a childhood population. ${ }^{3}$ In adults quite considerable within subject variability in $\mathrm{PD}_{20}$ to methacholine has been observed during a 1 year period, ${ }^{4}$ and a childhood population study found that methacholine $\mathrm{PD}_{20}$ varied by $>4$ doubling doses within the course of a year in $33 \%$ of the subjects.

We would suggest that more care should be taken to define the precise measure of AHR used before comments can be made about its sensitivity and specificity in an epidemiological survey. The medium term temporal variation in AHR seen by a number of researchers is another measure which may make it difficult to make useful comparisons between populations.

R A Primhak

Sheffield Children's Hospital, Western Bank, Sheffield S10 2TH, UK

C V E Powell

Departments of Emergency Medicine and Genera Paediatrics, Royal Children's Hospital, Parkville, Victoria 3052 and University of Melbourne,

\section{References}

1 Peat J, Toelle B, Marks G, et al. Continuing the debate about measuring asthma in population studies. Thorax 2001;56:406-11

2 Haby M, Anderson S, Peat J, et al. An exercise challenge protocol for epidemiological studies of asthma in children: comparison with histamine challenge. Eur Respir J 1994;7:43-9.

3 Powell C, White R, Primhak R. Longitudinal study of free running exercise challenge: reproducibility. Arch Dis Child 1996;74:126-30

4 Trigg C, Tooley M, D'Souza M, et al. Factors affecting the long-term variability of bronchial responsiveness in an adult general practice population. Eur Respir J 1994;7:703-9.

5 Clough J, Williams J, Holgate S. Profile of bronchial responsiveness in children with respiratory symptoms. Arch Dis Child 1992;67:574-9.

\section{Authors' reply}

Primhak and Powell make the valid point that the presence of airway hyperresponsiveness (AHR) is not an absolute attribute. Abnormal AHR represents one end of a continuum of responsiveness. Furthermore, the distribution of that continuum varies according to the nature of the direct or indirect stimulus that is applied.

In our studies, referred to in the review, we have defined abnormal airway responsiveness as a decline of more than $20 \%$ in forced expiratory volume in 1 second $\left(\mathrm{FEV}_{1}\right)$ after inhalation of a cumulative dose of histamine of $\leqslant 3.9 \mu \mathrm{mol}$. Using this criterion, the presence of AHR is a useful marker of airway abnormality consistent with asthma in epidemiological studies ${ }^{1}$ and is also predictive of the subsequent course of the disease. ${ }^{2}$ We acknowledge that other criteria for the presence of AHR have not been evaluated as extensively in epidemiological studies. However, there is evidence that at least some indirect agonists, such as non-isotonic aerosols and exercise, also have a high level of specificity but only moderate sensitivity as markers of asthma symptoms. ${ }^{34}$

J K Peat, B G Toelle, G B Marks, C M Mellis

Institute of Respiratory Medicine, University of

Sydney, Box M77, Missenden Road P O, Camperdown, NSW 2050, Australia

\section{References}

1 Toelle BG, Peat JK, Salome CM, et al. Toward a definition of asthma for epidemiology. Am Rev Respir Dis 1992;146:633-7.

2 Peat J, Toelle B, Salome C, et al. Predictive nature of bronchial responsiveness and respiratory symptoms in a one year cohort study of Sydney schoolchildren. Eur Respir J 1993;6:662-9.

3 Smith C, Anderson S. Inhalation provocation tests using nonisotonic aerosols. J Allergy Clin Immunol 1989:84:781-90.

4 Haby M, Peat J, Mellis C, et al. An exercise challenge for epidemiological studies of childhood ashma: validity and repeatability. Eur Respir J 1995;8:729-36.

\section{One fibre or many; what causes mesothelioma?}

In a recent case $(00 / \mathrm{TLQ} / 1284)$ in the Queen's Bench Division of the High Court in England, a widow sued on behalf of her husband who had died at the age of 60 of mesothelioma. Unusually for such cases, Mr Justice Curtis found for the defendants, and the grounds for his judgement were sufficiently curious to be of general interest and worthy of debate.

It was not disputed that the deceased had been exposed to substantial quantities of asbestos during two periods of employment, nor that there had been a breach of statutory duty by his employers at that time. The judgement was based, however, on the expert and agreed opinion of "two most highly qualified medical men". In their joint report and oral evidence, the judge believed these doctors to have stated that mesothelioma is the consequence of malignant transformation in a single cell, the result of a hit by either one or several fibres. This led the judge to reason that, although a fibre or fibres inhaled during one 
or other period of employment may well have led to the fatal cellular transformation, it was not possible to say which, and he was therefore unable to find either responsible.

In coming to his judgement, Mr Justice Curtis made a distinction between causation and risk factors. In his words "the only relevance of the number of fibres is in connection with the risk of contracting the disease". He was thus dissuaded from being influenced by any evidence that might have shown a relationship between risk of mesothelioma and dose of asbestos, although there is much such evidence from studies both of human lungs and of animals.

I have heard the view expressed before that one fibre causes mesothelioma. It depends what you mean by "cause". It is in one sense obvious nonsense. We all have millions of asbestos fibres in our lungs and the likelihood of us developing mesothelioma depends on how many millions. This means that the disease is dose related. The problem in this case arose from confusing the disease mesothelioma with transformation in a cell, which may be a factor in the development of the disease. Take the case of the butterfly flapping its wings in the Amazon rain forest. It may be possible for an ingenious QC to prove that the hurricane that hit the coast of west Africa was caused by that insect's action, but the other side would surely point to other risk factors that, taken with the action of the butterfly, contributed significantly to the disaster.

Is it really possible to say that the only and necessary cause of mesothelioma is transformation in a cell? Are we sure that the milieu in which that cell lives and divides is not influential? Are we sure that inflammation in the tissue involved is not an important precondition for the development of the disease? Are we sure that the action of asbestos on other cells does not interfere with the natural defences that would otherwise eliminate the transformed cell? Are we sure that genetic factors and viruses do not also determine whether the transformation occurs or succeeds in overcoming the body's defences? Or looked at another way, experimentally, how many rats would have to be used to produce one mesothelioma after injection of one fibre into the peritoneum? Of course, no one has ever shown that one fibre causes mesothelioma. All that has been conjectured is that the malignant cells that form part of the tumour may be the genetic offspring of one transformed cell.

The judge appears in this case to have been persuaded to accept a naïve view of causation-that disease has one ultimate cause. Most who have studied the causation of disease would argue that the likelihood of disease occurring in any individual is influenced by multiple factors, the outcome of inherited and acquired susceptibility and environmental precipitants. In the case of mesothelioma, a very heavily asbestos exposed individual may have a one in 10 lifetime risk of the disease. Most of us, with very small incidental exposures, have about a one in 1 million annual risk. The risk varies with the length and intensity of exposure, as assessed by the individual's occupational history. We know from animal studies that asbestos fibres do indeed cause mesothelioma, so this evidence of a dose related association strongly suggests that factors other than transformation of one cell are also, and critically, responsible for the disease. Among these is likely to be inflammation in the pleura initiated by the presence of many fibres. Such inflammation may not only result in malignant transformation of many cells, but may also inhibit the natural mechanisms whereby such cells are eliminated. If this is true, and it is certainly more plausible than the one fibre theory, then mesothelioma is caused by the access of large numbers of fibres to the mesothelial tissue. Since it is a dose related disease, it may be argued that all exposures to asbestos before a critical time would be expected to have contributed to the causation of the disease. Thus, attribution of blame should be on the basis of relative intensity and duration of exposure in different trades.

The moral of this story is that lawyers are clever people and part of their business is the meaning of words. The word "cause" is one that requires a bit of thought. My Shorter Oxford Dictionary devotes a column to it.

A Seaton

Department of Environmental and Occupational Medicine, Aberdeen University Medical School, Foresterhill, Aberdeen AB25 2ZP, UK a.seaton@abdn.ac.uk

\section{Mesothelioma}

We write as the three medical witnesses who provided evidence (all in writing, two orally) to the Court in the case referred to by Professor Seaton. Essentially we agree with his analysis. The medical evidence presented to the Court made it clear that the risk of mesothelioma increases in relation to the dose of asbestos and that it is not possible to identify the particular fibre or fibres involved in the genesis of a particular mesothelioma. From an epidemiological standpoint it is therefore appropriate to regard all sources of significant exposure as having contributed to causation of the disease, in the same way that all cigarettes smoked would be considered to have contributed to causation of a lung cancer.

Mr Justice Curtis, however, accepted the invitation of Leading Counsel for one of the defendants to adopt a strictly mechanistic approach to causation. He decided that, because the claimant could not show whether the fibre or fibres actually involved in the genesis of the tumour were derived from either or both of two sources of exposure, causation could not be established against either of two defendants.

More recently, a different view has been taken in a similar case by Mr Justice Mitting (Queen's Bench Division C20010111) He considered that there was "no substantial difference between saying that what the defendant did materially increased the risk of injury to the claimant and saying that what the defendant did made a material contribution to his injury". It would be "wholly artificial to require a claimant to prove which fibre or fibres, inhaled in whose employment in precisely what circumstances, caused or set off or contributed to the process by which one or more mesothelial cells become malignant". He concluded that breach of duty on the part of both defendants caused the mesothelioma.

Both cases are soon to be considered by the Court of Appeal and the outcome will determine whether the many mesothelioma victims who happen to have derived their asbestos exposure from more than one source are to be left without redress.

R Rudd

Medical Oncology Department, St Bartholomew's Hospital, London EClA 7BE, UK R.M.Rudd@qmul.ac.uk

J Moore-Gillon

Respiratory Medicine Department, St Bartholomew's Hospital, London EC IA 7BE, UK
M Muers
Respiratory Unit, The General Infirmary at Leeds,
Leeds LS1 3EX, UK;
amanda.jones@leedsth.nhs.uk

\section{Statement on malignant mesothelioma in the UK}

We would like to provide the following additional material to Appendix 3 "Sources of information and help available for patients and carers" which appeared on pages 263-4 of the BTS statement on malignant mesothelioma in the UK published recently in Thorax. ${ }^{1}$

The following Asbestos Support Groups are the major practical sources of information in the UK for people with asbestos related diseases. Most provide a drop in and telephone service, giving confidential free advice and support to patients and families. They also have particular expertise in the field of industrial injury benefits and government and civil compensation claims. Although most of the groups are in the north of England, telephone queries from any part of Great Britain are acceptable to them.

Manchester (tel: 0161953 4037)

Sheffield (tel: 01142823212 or 01709513 587)

Liverpool (tel: 0151236 1895)

Bradford (tel: 01274393949 )

West Yorks (tel: 01132439979 )

Cheshire (tel: 01928 576641)

Nottingham (tel: 01159275108 )

In Scotland:

Clydeside Action on Asbestos (tel: 0141552 8852)

Clydebank Asbestos Group (tel: 0141 951 1008)

Other important sources of help and information are:

The Macmillan Mesothelioma Information Line (tel: 0113206 6466; email: mavisro@ulth.northy.nhs.uk) and the Occupational and Environmental Diseases Association (OEDA), both of which were mentioned in the original statement.

M Robinson

Mesothelioma Information Service, Cookridge Hospital, Leeds LS16 6QB, UK; mavisro@ulth.northy.nhs.uk

J Wiggins

Deparment of General Medicine, Wexham Park Hospital, Slough, Berkshire SL2 4HL, UK

\section{Reference}

1 British Thoracic Society Standards of Care Committee. Statement on malignant mesothelioma in the United Kingdom. Thorax $2001 ; 56: 250-65$.

\section{Asymptomatic pulmonary involvement in RA}

Dawson et al ${ }^{1}$ found HRCT evidence of fibrosing alveolitis (FA) in 19\% of 150 outpatients with rheumatoid arthritis (RA). The presence of FA did not relate to previously described predisposing factors such as male sex, nodular and/or extra-articular disease, disease duration and severity. Moreover, the authors did not find any relation with respiratory symptoms such as dyspnoea or cough, chest radiographic appearance of FA, or restrictive pattern at pulmonary function tests. The only features significantly associated with FA on the HRCT scan were the presence of bibasal crackles and the reduction in carbon monoxide transfer factor (TLCO). These findings are more difficult to explain, especially considering that FA was defined as an HRCT pattern 
"typical" of usual interstitial pneumonia according to a more recent classification. Other studies had shown a high prevalence of FA, even in recent onset RA. ${ }^{3}$

We have recently investigated the presence of pulmonary disease in 24 consecutive patients with RA without respiratory symptoms or signs and a normal chest radiograph. In all these patients we performed a chest HRCT scan as well as complete pulmonary function tests (PFTs). Our patients were predominantly women $(22 / 24)$, of mean age 49.4 years (range 26-72), and $46 \%$ of them had a disease duration of less than 2 years. Only 33.3\% were current smokers. We found TLCo of $<75 \%$ in $50 \%$ of the patients; two patients had obstructive PFT and one patient restrictive PFT. Pleuropulmonary alterations were detected in $20.8 \%$ of the patients on the HRCT scan, but only one patient had an HRCT pattern suggestive of FA according to stringent criteria. ${ }^{2}$ In all the other patients the alterations observed were mild and non-specific (pleural abnormalities, septal and non-septal lines, micronodules). Our data confirm a rather high prevalence of pleuropulmonary alterations in patients with RA, even in the absence of respiratory symptoms. However, we found evidence of FA much less frequently than Dawson et al. ${ }^{1}$ This difference may only be partly explained by patient selection: not all our patients had respiratory symptoms and almost half of them had RA of short duration. The newly available diagnostic techniques such as HRCT scanning have increased interest in evaluating patients with connective tissue diseases. However, the clinical relevance of the frequently observed pulmonary alterations in patients with RA has still to be elucidated, as well as the best diagnostic approach to respiratory involvement in this multifaceted disease.

G Provenzano

Division of Respiratory Diseases, A.O. "Villa Sofia CTO", 90143 Palermo, Italy giuseppe.provenzano5@tin.it

\section{References}

1 Dawson JK, Fewins HE, Desmond J, et al.

Fibrosing alveolitis in patients with rheumatoid arthritis as assessed by high resolution computed tomography, chest radiography, and pulmonary function tests. Thorax 2001;56:622-7.

2 Katzenstein AA, Myers L. Idiopathic pulmonary fibrosis: clinical relevance of pathologic classification. Am J Respir Crit Care Med 1998;157:1301-15.

3 Gabbay E, Tarala R, Will R, et al. Am J Respir Crit Care Med 1997;156:528-35.

\section{CD-ROM REVIEW}

\section{Paediatric Respiratory Examination}

C O'Callaghan, W Stannard. Leicester, UK: OCB Media, 2001, £49.95 (students $£ 25.00)$. ISBN 190403906

This CD-Rom has been produced as a multimedia based interactive learning tool for a wide spectrum of healthcare professionals including general practitioners, junior doctors, nurses, physiotherapists, and medical students. As such, it will find wide appeal to those who wish to learn or brush up on paediatric respiratory examinations.

The authors and designers should be congratulated for producing a CD-Rom which is highly intuitive and easy to navigate. The pictures, videos and case studies are of high quality and can be viewed with an informative running commentary, although unfortunately the commentaries cannot be fast forwarded or rewound to find passages of particular interest. The case studies provide excellent examples of classic paediatric auscultatory findings such as wheeze, stridor, and the fine inspiratory crepitations of bronchiolitis.
The Paediatric Respiratory Examination CDRom serves as a good template on which other system examination CD-Roms could be designed.

K Tan

\section{NOTICE}

\section{Scadding-Morriston Davies Joint} Fellowship in Respiratory

\section{Medicine 2002}

This fellowship is available to support visits to medical centres in the UK or abroad for the purpose of undertaking studies related to respiratory medicine. Applications are invited from medical graduates practising in the UK, including consultants and irrespective of the number of years in that grade. There is no application form, but a curriculum vitae should be submitted together with a detailed account of the duration and nature of the work and the centres to be visited, confirming that these have agreed to provide the facilities required. Please state the sum of money needed for travel and subsistence. A sum of up to $£ 15000$ can be awarded to the successful candidate, or the sum may be divided to support two or more applications. Applications should be sent to Dr I A Campbell, Secretary to the Scadding-Morriston Davies Fellowship, Llandough Hospital, Penarth, Vale of Glamorgan CF64 2XX, UK by 31 January 2002.

\section{CORRECTION}

In the article entitled "Influence of age and disease severity on high resolution CT lung densitometry in asthma" by F Mitsunobu et al which appeared in the November 2001 issue of Thorax (2001:56:851-6), an error occurred in table 3 on page 854 . The heading to the first column which appeared as "MLD (HU) $\left(R^{2}=\right.$ $0.0524)$ " should read "MLD (HU) $\left(R^{2}=\right.$ $0.524)^{\prime \prime}$. 